\title{
A NEW SMALL POTATO PLANTER FOR EGYPTIAN AGRICULTURE
}

\author{
Ismail Z. Ebrahem, Amer Eissa Ayman, Riccardo Guidetti
}

\section{Introduction}

The potato is a major strategic crop in Egypt, second only to cotton. It represents about $25 \%$ of total Egyptian agricultural exports, while cotton accounts for $40 \%$. It is ranked as one of the most important vegetable crops. At the same time, despite the increase in potato yield from $16.68 \mathrm{t} /$ hectare in 2004 to 21.5 t/hectare in 2006 , potato production does not meet the dramatic increase in population and exportation. In fact, potato tuber planting methods in Egypt can be divided into manual (traditional) and mechanical methods. But, unfortunately, the manual method of potato planting still represents more than $85 \%$ all potato-cultivated area [Agric. St. Yearbook 2008] and is very laborious, tedious, and slow. It requires about $160 \mathrm{man} /$ hour hectare.

Special attention must be given to establishing a new suitable technique for potato planting that influences the yield. There is a trend toward planting tuber pieces of potato with previously grown sprouts. Increasing the productivity of potato in a shorter period is the main goal. This can be achieved by using suitable technology. The suggested technique is divided into two main steps. The first includes the method of tuber cutting, while the second investigates sprout growing methods. The need of planting tuber with previously grown sprouts refers to the fact that the potato field is planted three times per year in the same field and the interfering periods between them not enough for good aeration and soil preparation. Therefore, it is important to try to reduce the growing stage by using previously grown sprouts in planting [Ismail 2004; Hatem 2002; Alojzy 1989].

A new potato planter was developed for use in

Paper received 08.01.2010; accepted 19.09.2011

ISMAIL Z. EBRAHEM, Associate professor, Department of Agricultural Engineering, Mansoura University, Egypt; AMER EISSA AYMAN, Associate Professor, Department of Agricultural Engineering, King Faisal University, Saudi Arabia; RicCARDo GuideTti, Associate Professor, Department of Agricultural Engineering, Università degli Studi di Milano. Corresponding author: aymanhafiz@kfu.edu.sa
Egypt. Imported planters' feeding systems are unable to reduce damage during planting because the tubers are dropped from too high, resulting in more deviations in the uniformity of potato placement. In order to increase potato production and potato quality, there is a need to develop and use modern and improved potato machinery technology, especially sprouting tuber planters because sprout tuber planting achieves early germination, which leads to early harvesting and helps create strong roots and dispose of un-sprouted tubers.

Buitenwerf [2006] and Iritani [2002] created a theoretical model to determine the origin of uniformity deviations in potatoes placement (presence of voids and double potatoes). The model calculates the time interval between each successive potato touching the ground. Spacing was shown to affect yield when the coefficient of variation reaches 37\%. Celik [2007] and James [1999] evaluated four types of seeders based on tuber spacing, depth uniformity, and plant emergence at three forward speeds $\left(3.6,5.4\right.$, and $\left.7.2 \mathrm{kmh}^{-1}\right)$; results indicated that the forward speed only significantly affected the mean emergence time $(\mathrm{P}<0.05)$. As forward speed increased, mean emergence time decreased. But Griepentrog [1998] and Karayel and Ozmerzi [2002] demonstrate uniform seed spacing and depth results in better germination and emergence and increased yield by minimizing competition between plants for available light, water, and nutrients.

Ismail [2006] showed that only $10 \%$ of the variation in tuber mass was attributable to tuber size when spacing was $30 \mathrm{~cm}$. The resultants also showed that the most suitable tuber piece size must be in the range of 30-50 g when spacing was $25 \pm 5 \mathrm{~cm}$ and added that the life-period of potato plant takes is approximately 120 days. This period can be divided into the following three stages:

Stage one: starts from the first day of planting until the appearance of the tubers. It takes about 6 to 8 weeks;

Stage two: takes about two weeks from the appearance of potato tubers; and

Stage three: starts from tuber formation until harvesting time. 
Stage one is considered the longest stage. Therefore, it is important to try to reduce the duration of this stage by using previously grown sprouts in planting. Applying this technique requires modification of the potato planter.

In all available potato planter machines built in Egypt, usually in local workshops, the damage to the tuber pieces that have grown buds will increase as a function of the friction between the tuber and the guide surface of the feeding system. Nevertheless, this phenomenon affects the quality of planting.

The aims of this study are as follows:

1. To develop and modify a small potato planter using a feeding system with chain-spoons to plant potato tuber pieces with previously grown sprouts;

2 . To study the behaviour of the modified planter during its action considering the new geometric parameters.

\section{Design consideration}

A classical design of a chain-spoon feeding system is set vertically, and the buckets are provided with indented spoons. A single tuber is manually fed to every spoon, which lifts upward. Then, the tuber is dropped down on the back of the next spoon in the conveyor. The analysis of the planter points out that the chainspoons expose the tuber pieces to friction between its surface and the conveyor guide until it leaves the feeding unit. The tuber pieces will be exposed to damage every revolution of the feeding system. Mainly, there are three zones of damage, as indicated in Figure 1.

\subsection{First Damage Zone}

Primary observation during one revolution of the chain-feed system indicated that the tuber piece is conveyed to the maximum point on the chain-feed and then is dropped for a fraction of a second. Then, the conveying velocity of the chain-spoon will push the tuber toward the next spoon. The direction analysis of the falling of tuber pieces, as shown in Figure1A, considers that the direction of motion, with neglected air resistance, is subjected to the conveying velocity of chain-spoon, the mass of tuber piece, and gravity.

\subsection{Second Damage Zone}

The tuber on the spoon back, Fig. 1-B, will be exposed to the following during conveying:

a) Friction force between the feeding guide and the tuber surface;

b) The mass of tuber pieces.

On the whole, the forces are in the opposite direction of tuber motion.

\subsection{Third Damage Zone}

The geometrical analysis of the fall from the feeding device to the furrow bottom plays an important role in determining the values of tuber damage. Logically, the motion of the exiting tuber chain-feed is relative to the two velocity vectors, namely the peripheral speed of this unit and the forward speed of the planter.

An analysis of the maximum kinetic energy upon the tuber pieces will occur at the maximum tuber speed at the moment it leaves the feeding unit; at the free fall height and at the mass of the potato.

To avoid these disadvantages, the structure of a new chain feeder was developed. The spoons were replaced with simple cups (Fig. 2). They are designed to convey the tuber and to keep it from movement until

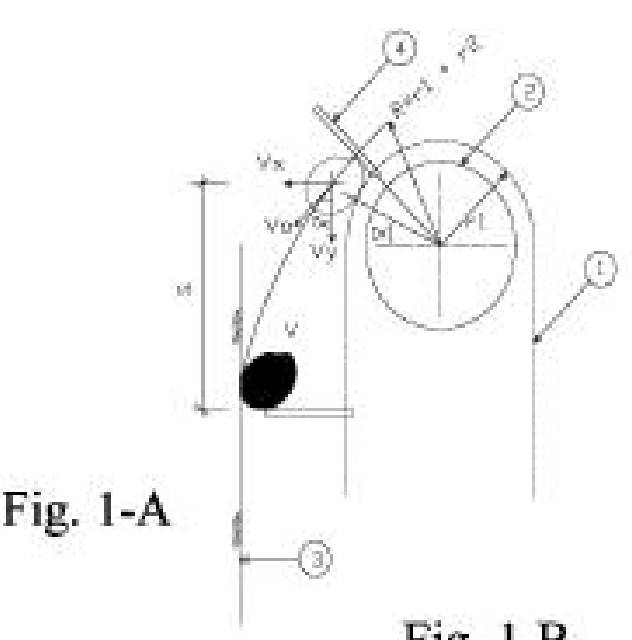

Fig. 1-B
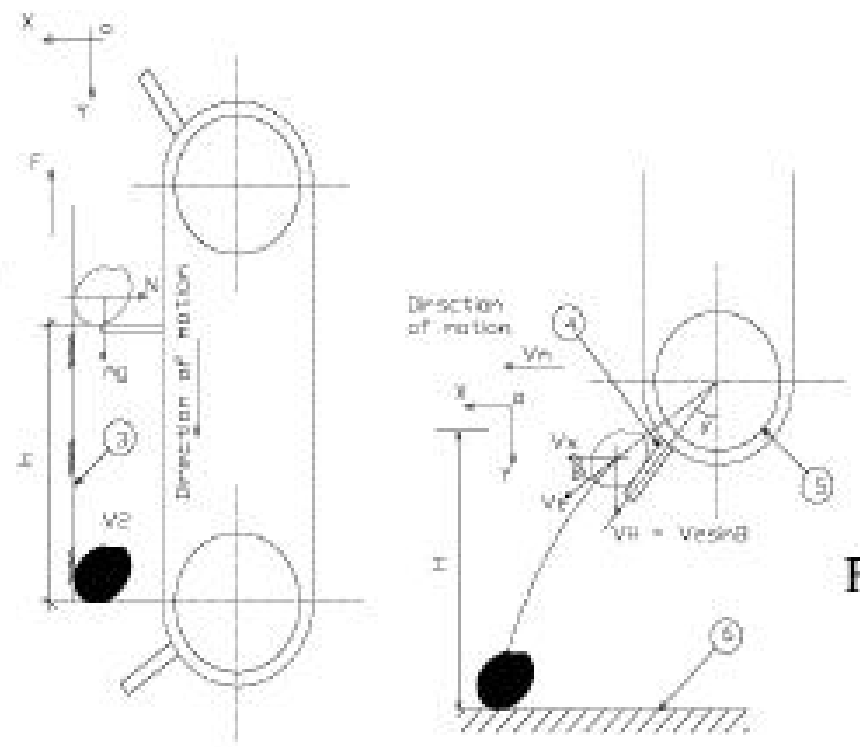

Fig. 1-C

Fig. 1 - A: The first damage zone. Fig. 1-B: The second damage. Fig. 1-C: The third damage. 1- Chain-feed device. 2- Driven gear. 3- Guide surface. 4- Spoon. 5- Driver gear. 6- Soil surface 

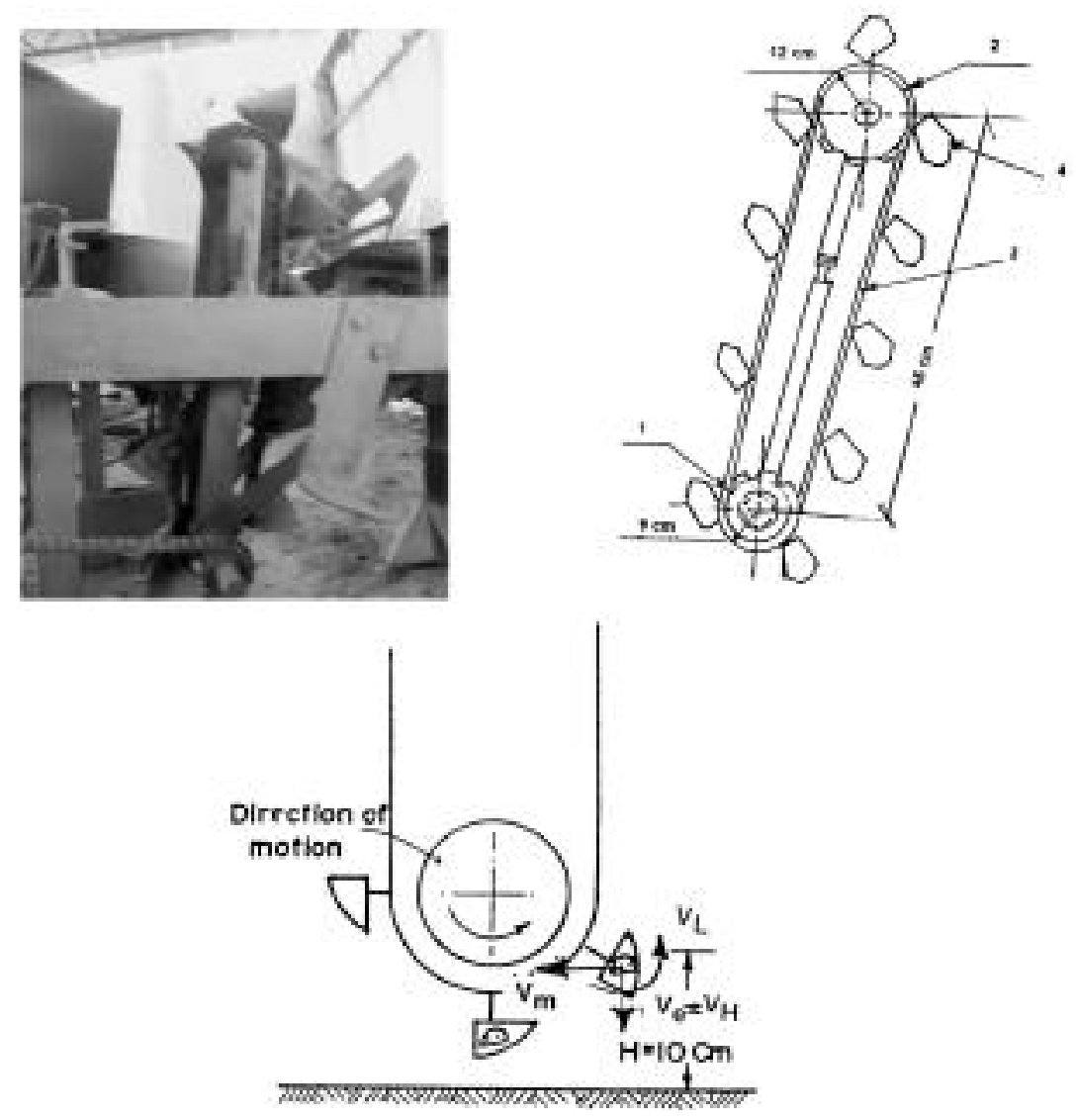

Fig. 2 - Reducing the free fall height of tuber pieces. 1- Driver gear 2- Driven gear 3- Chain 4- Cup

exiting from the feeding system. Consequently, the tuber did not:

a) Drop down on the next spoon in the conveyor (first zone of tuber damage);

b) Act upon the friction force between its surface and the feeding system guide (second zone of tuber damage).

To overcome tuber damage in the third zone, the exiting tuber angle and the free fall height may be minimized. Then, the following attempts are carried out:

1) In the new design, the tuber exiting unloading angle (Fig. 2) makes the tuber drop vertically.

2) The free fall height " $H$ " was reduced from 30 to 10 $\mathrm{cm}$.

\section{Materials and methods}

\subsection{Developed Potato Planter}

The chain-feed of the potato planter was developed to plant tuber pieces with grown buds. The steel frame consists of parts that can be easily assembled and modified (Fig. 3): The structure is made of two main square beams with a cross-section of $100 \times 100 \mathrm{~mm}$; one in front (800 mm length) and the second one in the back $(1500 \mathrm{~mm})$. The main beams were connected to each other via two units $(1300 \times 300 \mathrm{~mm})$ containing the two feeding systems. Two furrow openers (shoe shape type) are fixed in the front beam (Fig. 3). Each of them can be adjusted to control the depth of the furrow. The feeding system consists of two units; each unit contains ten cups (Fig. 2). The closing system consists of three furrow closing units located at the back end. The transmission system was constructed to control the number of cubes per revolution and was adapted to yield rows of tubers every $25 \mathrm{~cm}$. To prevent slipping, a chain-sprocket transmission system is used to transmit the motion from the planter wheel $(\mathrm{D}=440 \mathrm{~mm})$ to both feeding devices. The tuber box is designed to easily feed the tubers.

\subsection{Reference Potato Planter}

A classical potato planter with a typical chain feed system is used for a comparative analysis. The machine was built in the University of Mansoura's workshop with the same frame as the new one but with a classical chain feed and geometrical configuration that is usually used in Egyptian potato planters. Also, this planter's feed system holds ten potatoes.

\subsection{Planter preparation}

The planter is calibrated and adjusted to achieve 25 $\mathrm{cm}$ between tubers in a row, $71 \mathrm{~cm}$ between two rows, and $6 \mathrm{~cm}$ planting depth, referring to a previous test [lsmail 2004]. 


\subsection{Tuber Preparation}

The sprouts are left to grow on the tuber. After that, the tubers are cut into pieces. Each piece has one or more buds. Six plant benches are installed inside a glass room to be used for germination tests. Each room has a surface area of $1 \mathrm{~m}^{2}(2 \mathrm{~m}$ long $\times 0.5 \mathrm{~m}$ wide). The surface of the plant benches contained a straw bed. The tuber pieces are distributed on them with a row distance of $10 \mathrm{~cm}$ and tuber distance in the rows of $5 \mathrm{~cm}$. A tank of water is connected to the plant benches using a $12 \mathrm{~mm}$ diameter plastic tube to keep the straw bed wet. Temperature and straw bed moisture content were regulated under the control system.

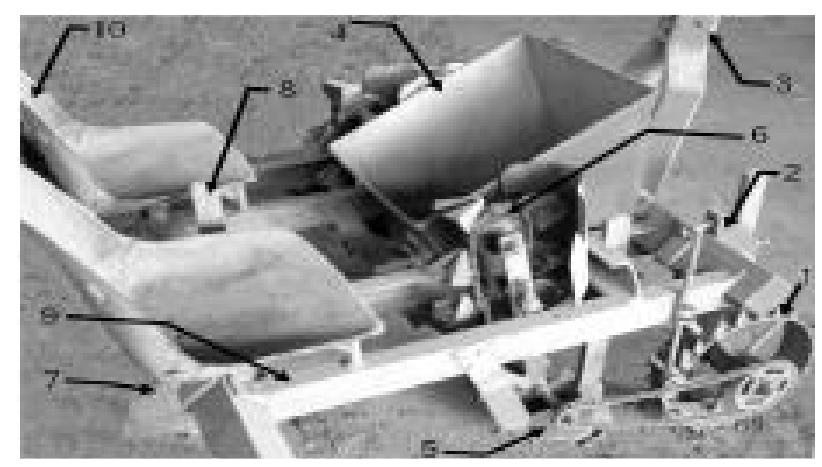

Fig. 3 - The developed potato planter

1- Land wheel 2- Control beam 3- Hitching point 4- Tuber box 5- Furrow opener 6- Feeding device 7- Closing device 8- Beam 9- Frame 10Labor chair

\subsection{Experimental methodology}

The experimental study provides a comparison between a classical potato planter and the new one. Each test is repeated three times.

The field is divided into plots $(22.5 \times 50 \mathrm{~m})$ and sub plots $(7.5 \times 50 \mathrm{~m})$. The experiments are carried out at EI-Tawella, Dakahilia Governorate private sector farm.

The mechanical analysis of the experimental soil was $21.05 \%$ sand, $30.0 \%$ silt, $47.2 \%$ clay, and 1.75 $\%$ coarse sand at a depth from zero to $20 \mathrm{~cm}$. The plots are selected at random from each treatment after plowing; harrowing and soil leveling is done traditionally.

The following measurements evaluate the investigated potato planter:

1- Tuber spacing is evaluated by measuring the space between tubers in rows for each test. The frequency of tuber spacing is computed according to an analysis of the single-variable method.

2- Tuber void (\%) is the void when the distance $\left(\mathrm{S}_{\mathrm{c}}\right)$ between planted tubers in rows is twice greater that of pre-adjusted distances $(25 \mathrm{~cm})$. Tuber voids are calculated for each treatment by estimating the number of $\mathrm{S}_{\mathrm{c}}$ in each experimental plot as follows:

$$
\mathrm{V}_{\mathrm{t}}=\frac{\mathrm{m}_{\mathrm{n}}}{\mathrm{M}} \times 100
$$

Where:

$\mathrm{V}_{\mathrm{t}}=$ percentage of tuber void, $\%$;

$\mathrm{M}=$ theoretical number of cups at limited time of working feeding mechanisms; and

$\mathrm{m}_{\mathrm{n}}=$ number of spacing $\left(\mathrm{S}_{\mathrm{c}}\right) \geq 2 \mathrm{~S}_{\mathrm{t}} \geq 50 \mathrm{~cm}$ at the same limited time.

3- Tuber doubles (\%) are calculated when the distance between tubers in a row $\left(\mathrm{S}_{\mathrm{c}}\right)$ is half or less than the pre-adjusted space in the row $\left(\mathrm{S}_{\mathrm{t}}\right)$ I.e., $\mathrm{S}_{\mathrm{c}} \leq\left(\mathrm{S}_{\mathrm{t}} / 2\right) \leq$ $12.5 \mathrm{~cm}$; it is calculated using Ismail's [2004] method.

4- The quality evaluation of the potatoes is done by determining shatter bruises via visual examination. The length of each bruise in the skin is measured using a handhold caliper. The bruise depth is located by slicing the potato tuber perpendicularly and along the depth of the cut. The depth is then measured using a handhold caliper. The shatter index (SI) is estimated using the formula below [Grant 1985]:

$$
\mathrm{SI}=\sum_{\mathrm{n}-\mathrm{1}}^{\mathrm{n}=\mathrm{N}} \frac{d_{1} \times \mathrm{h}_{1}+\ldots \ldots \ldots \ldots \ldots \ldots+d_{s} \times \mathrm{h}_{\mathrm{n}}}{\mathrm{N}}
$$

Where:

$\mathrm{d}=$ Length of shatter, $\mathrm{mm}$

$\mathrm{h}=$ Depth of shatter, $\mathrm{mm}$

$\mathrm{N}=$ Number of observations per tuber

\section{Results and discussion}

\subsection{Tuber spacing in rows}

The spaces between tuber pieces in a row are evaluated as a tuber deviation percentage, which is estimated using the feeding devices before and after modifications are shown in Figure 4. With the classical configuration (Fig. 4.A), the result indicated that $50.62 \%$ (sum of the tuber deviation $(\%$ ) between 20 $\mathrm{cm}$ and $30 \mathrm{~cm}$ ) of tuber pieces of $40 \mathrm{~g}$ are distributed in spaces use $20-30 \mathrm{~cm}$ (the pre-adjusted space of 25 $\mathrm{cm})$. The remaining $49.38 \%$ is distributed outside this range. The corresponding remainder percentage is about $68 \%$ for the feeding device after modification (Fig. 4.B). This may be because the free fall height in old designs is higher than in developed ones. From the above result, and with respect to the theoretical trend, the suggested feeding mechanism is suitable under Egyptian conditions (tuber pieces $40 \mathrm{~g}$ ).

\subsection{Tuber voids}

The results of the tuber void ratio $\left(\mathrm{V}_{\mathrm{t}} \%\right)$ versus planting speed are shown in Figure 5. The figure displays the results obtained from both machine designs; there is no significant difference in the field void because the two planters have the same productivity feed chain (10 tubers).

The general trend of this relationship is that the percentage of tuber void increased as planting speed increased. Interestingly, the increasing rates of $\mathrm{V}_{t}$ in tuber pieces weighing $50 \mathrm{~g}$ is higher than in those of 

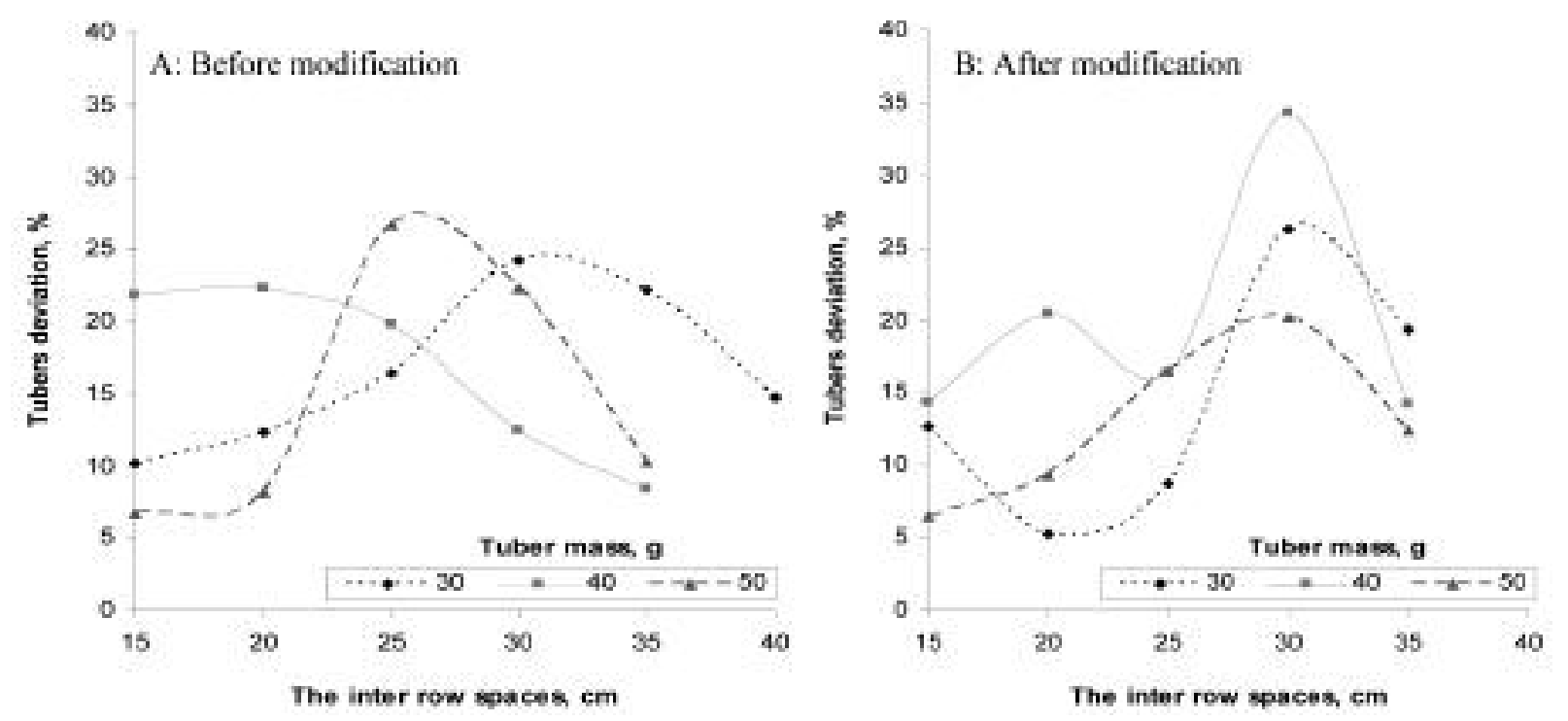

Fig. 4 - Tuber deviation frequency: before (A), after (B) planter modification.

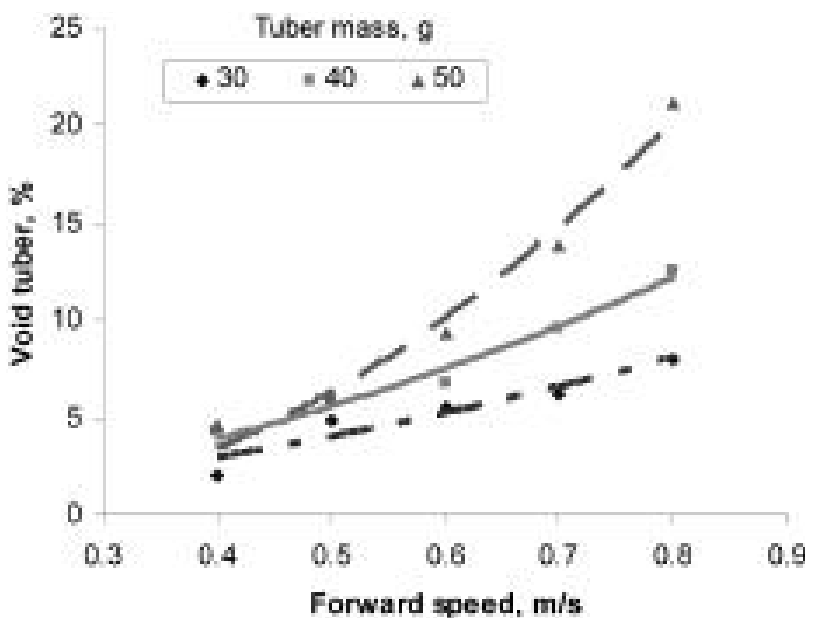

Fig. 5 - Tuber void ratio $\left(\mathrm{V}_{\mathrm{t}} \%\right)$ versus planting speed. tuber pieces weighing 40 and $30 \mathrm{~g}$. These differences may be due to the low ability of workers for catching larger-sized tubers. In addition, Figure 5 shows that the void ratio is largely valid within a planting speed range of 0.6 to $0.8 \mathrm{~m} / \mathrm{s}$, more than those from 0.4 to $0.6 \mathrm{~m} / \mathrm{s}$ for all tuber masses. These variations are due to the relatively higher peripheral speed of feeding mechanism. The average $\mathrm{V}_{\mathrm{t}}$ of tuber mass of $50 \mathrm{~g}$, which is the highest $(10.76 \% \pm 5.95 \%)$, followed by tuber pieces of $40 \mathrm{~g}(8.2 \% \pm 3.54 \%)$, and tuber pieces of $30 \mathrm{~g}(5.2 \% \pm 2.05 \%)$.

\subsection{Tuber doubles}

The contour plot of the tuber doubles (percentages) versus planting speed with different masses of tuber pieces $(30,40$ and $50 \mathrm{~g})$ are illustrated in Figure 6.

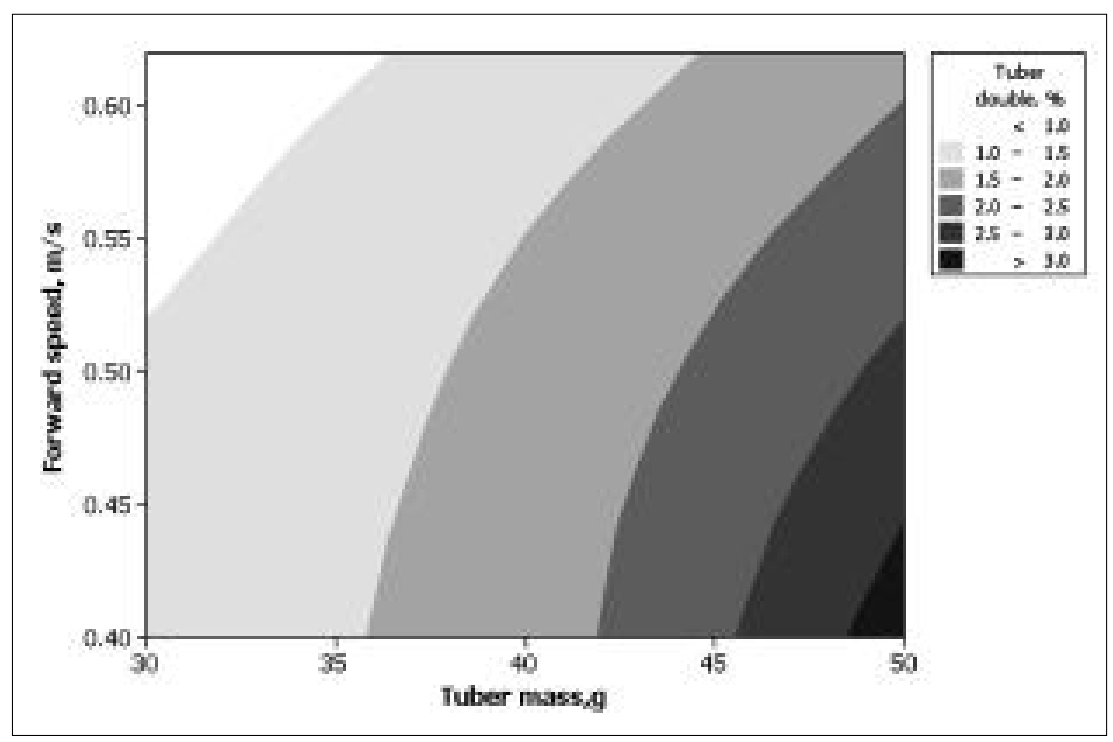

Fig. 6 - Contour plot of tuber double vs. forward speed and tuber mass. 


\begin{tabular}{|c|c|c|c|c|c|}
\hline \multirow{2}{*}{$\begin{array}{c}\text { Feeding } \\
\text { system, rpm }\end{array}$} & \multicolumn{2}{|c|}{ The developed potato planter } & \multicolumn{3}{c|}{ The old design } \\
\cline { 2 - 7 } & $\begin{array}{c}\text { Length of shatter, } \\
\mathrm{mm}\end{array}$ & Depth, mm & SI, \% & $\begin{array}{c}\text { Length of shatter, } \\
\text { mm }\end{array}$ & Depth, mm \\
\hline 5 & - & - & - & - & - \\
\hline 10 & 3 & 1 & 1.5 & 7 & 5 \\
\hline 15 & 11 & 3 & 31.0 & 21 & 7 \\
\hline 20 & 13 & 4 & 46.0 & 27 & 73.5 \\
\hline
\end{tabular}

TABLE 1 - Shatter bruise occurrences on both the new and old design of the potato planter.

The tuber double percentages are lower when planting tubers weighing $30 \mathrm{~g}$ versus with those weighing $40 \mathrm{~g}$ or $50 \mathrm{~g}$. This behaviour may be attributed to the fact that workers can handle large pieces easier than small ones. Moreover, the results revealed that the tuber doubles decrease with increasing planting speed. Also, in this case, there is no difference between the two machine designs.

\subsection{Tuber resistance to damage}

The shatter bruise is measured as a dependent variable to evaluate the investigated potato planter. The shatter bruise (SI-index) is improved by using the developed feeding system shown in Table 1. Significant differences $\left(\mathrm{P}_{\mathrm{r}}<0.05\right)$ were found in the shatter bruise when comparing investigated and common potato planters.

The table shows how the new configuration is able to yield potatoes with a much better quality index.

\section{Conclusion}

A new configuration of a potato planter feeding system was designed, developed, and tested for Egyptian agriculture. It was now oriented to use tuber pieces with sprouts grown. A new system for moving the tuber with tablespoons to avoid damage to the product was inspired by theoretical considerations [Buitenwerf 2006; Iritani 2002].

The results, related to the correct position in the field, showed that the new system should be able to place a major percentage of tubers between 20 and 30 $\mathrm{cm}$ in accordance with proper agricultural practices for ideal growth [Ismail 2006; Karayel 2002] than the reference planter.

The study of tuber voids or tuber doubles showed no significant differences between the two machine models because the productivity of the two feeding systems did not change (10 tuber each). The ideal tuber size, however, is $30 \mathrm{~g}$, since there were minor changes in voids at different speeds and fewer occurrences of double tubers; the most common Egyptian tuber piece dimension is $40 \mathrm{~g}$; the results obtained are comparable to the considerations already reported in the literature [Altuntas 2005].

The study of the quality of the samples, carried out by identifying the shatter index (SI\%), has instead led to the conclusion that changes help avoid damage to the tubers and its growth. Table 1 shows that at low speeds, the modified system has blurred the damage, while at high speed it is maintained at around 50\% compared to the reference planter.

The new system of tuber filing, therefore, increases the quality of productivity in Egyptian conditions.

\section{References}

Agric. St. Yearbook (2008). Published by Egyptian Ministry of Agric.

Alojzy Y.S., James L.H., Joseph J.P. and Denies L.C. (1989), Determine potato tuber resistance to impact damage. American potato Journal (APJ), April 6, vol. 66, 401-416.

Altuntas E. (2005), The effects of some operational parameters on potato planter's performance. AMA, 36(2): 7174.

Buitenwerf H., Hoogmoed W.B., Lerink P. and Müller J. (2006), Assessment of the Behaviour of Potatoes in a Cup-belt Planter. Biosystems Engineering, 95 (1): 35-41.

Celik A., Ozturk I. and Way T.R. (2007), Effects of various planters on emergence and seed distribution uniformity of sunflower. Applied Engineering in Agriculture Vol. 23(1): 57-61.

Gosensive F.G. and Ismail Z.E. (1985), Testing a new design for potato planter model KCM-6. Paper of Gorkaveckover. Selkhoz Aka., BSSR 78-85.

Grant S.W., Turecgyn M.T., Ashby B.H., Hallee N., Kfeinschmidt G. and Wheation F.W. (1985), Potato bruising during transport. ASAE paper No. 85. 6023, ASAE. St Jaseph M 49-85.

Griepentrog H.W. (1998), Seed distribution over the area. EurAgEng. 98-A-059, Oslo.

Hatem S.A., Ismail Z.E. and Aly Abo-Almged (2002), Development a planter use to plant tuber previously grown buds. J. Agric. Sci., Mansoura Univ. 19 (7): 2321-2343.

Iritani W.M., Thorntaon R., Weller L. and Leary G.O. (2002), Relationships of seed size, spacing, stem numbers to numbers of yield of russet Burbank potatoes. An potato J., 49: 463-469.

Ismail Z.E. (2006), A suitable potato planter uses to plant tuber pieces with previously grown sprouts. Mansoura University, Faculty of Ag., Ag. Eng. Dept. Conf. of Modern Techniques in Agricultural Engineering as a Tool for Community Service and Development of Environment, J. Agric. Sci. Mansoura Univ., 31 (7): 305-322.

Ismail Z.E. (2004), The first report of project (Developing the Metering Unite of the Pneumatic Planter) financed by Mansoura University researches unite. 
James W.C., Lawrence C.H. and Shih C.S. (1999), Yield losses due to missing plants in potato crops. Am potato J. 50: 345-352.

Karayel D. and Ozmerzi A. (2002), Effect of tillage methods on sowing uniformity for maize planting. Canadian Biosystems Engineering 44: 2.23-2.26.

\section{SUMMARY}

Reducing the tuber period for potato plants by planting previously grown sprouts is a new technique. Applying this new agricultural methodology requires modification of the potato planter. The theoretical analysis was carried out to obtain information that can help avoid tuber damage during feeding and until it exits the feeding system. Starting from these considerations, a new potato planter with a spoon-based feeding system was designed and built.

The tests conducted verified that the new system performed well when dividing tuber pieces into rows: considering the best growth spacing for potatoes is
$20 \div 30 \mathrm{~cm}$, the new system has a $68 \%$ distribution versus the $50,62 \%$ of the old one.

The tubers' spacing in rows are evaluated based on tuber voids and tuber doubles. The results show that there is no difference between the two systems' configurations, while a general consideration about our machine is that it is better at managing small tuber pieces. The void ratios are largely valid within the range of 0.4 up to $0.8 \mathrm{~m} / \mathrm{s}$ of planted speeds; moreover, the results revealed that the tuber doubles decrease by increasing planting speed and vice versa with tuber voids.

The quality of the potatoes planted is evaluated using the Shatter Index (SI \%), which shows how the new configuration is more delicate with the tuber pieces $(1.5 \%$ against $17.5 \%$ at $10 \mathrm{rpm}$ or $46 \%$ against $94 \%$ at rpm 20). The new configuration could be an interesting improvement for potato quality and Egyptian potato production.

Keywords: planter, tuber piece, quality, potato. 


\section{THE BUILT ENVIRONMENT OF FARM WINERIES: AN ANALYSIS METHODOLOGY FOR DEFINING META-DESIGN REQUIREMENTS}

Patrizia Tassinari, Sergio Galassi, Stefano Benni, Daniele Torreggiani

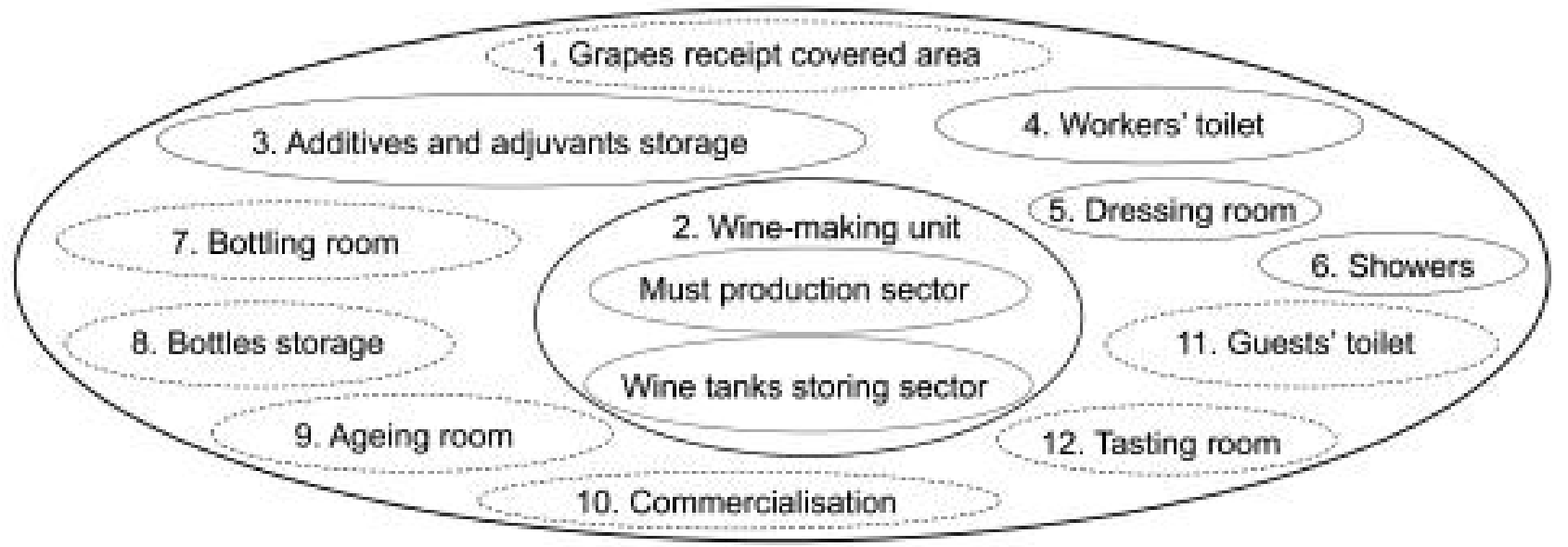

Fig. 6 - Conceptual scheme of the spatial units of a winery. Broken contour lines indicates rooms that may not be present, depending on process features and marketing choices. 